\title{
The American Society of Clinical Oncology-endorsed American Society for Radiation Oncology Evidence-Based Guideline of stereotactic body radiotherapy for early-stage non-small cell lung cancer: An expert opinion
}

Matthias Guckenberger, MD, ${ }^{\mathrm{a}}$ Joachim G. Aerts, MD, PhD, ${ }^{\mathrm{b}}$ Paul Van Schil, MD, $\mathrm{PhD},{ }^{\mathrm{c}}$ and Walter Weder, MD

\footnotetext{
From the a Department for Radiation Oncology, University Hospital Zurich, University Zurich, Zurich, Switzerland; ' Department of Pulmonary Diseases, Erasmus MC, Rotterdam, The Netherlands; ${ }^{\mathrm{c} D e p a r t m e n t}$ of Thoracic and Vascular Surgery, Antwerp University Hospital and Antwerp University, Antwerp, Belgium; and ${ }^{\mathrm{d}}$ Department of Thoracic Surgery, University Hospital Zurich, University Zurich, Zurich, Switzerland. Received for publication July 20, 2018; revisions received Sept 7, 2018; accepted for publication Sept 11, 2018. Address for reprints: Walter Weder, MD, University Hospital Zurich, Department of Thoracic Surgery Raemistrasse 100, CH-8091, Zurich, Switzerland (E-mail: walter.weder@usz.ch).

J Thorac Cardiovasc Surg 2019;157:358-61 $0022-5223 / \$ 36.00$

Copyright $(2) 2018$ Published by Elsevier Inc. on behalf of The American Association for Thoracic Surgery https://doi.org/10.1016/j.jtcvs.2018.09.107
}

Feature Editor's Note-After reading this Feature Expert Opinion, it should be more evident than ever that lobectomy is the current standard of care for patients with stage I non-small cell lung cancer (NSCLC) who are medically fit for operation. It is common, however, for fit patients with stage I NSCLC to perceive stereotactic body radiotherapy (SBRT) as an attractive option for the treatment of their disease. SBRT is a noninvasive, well-tolerated outpatient procedure, and the Internet is replete with favorable efficacy statistics for SBRT that cannot be appropriately interpreted without a certain background in the field. As is common with all new and exciting technologies, innovation is provided with an opportunity to outpace the standard of care. SBRT for NSCLC is a relatively young and rapidly evolving modality of radiotherapy that has shown favorable results for control of the localized tumor mass in patients with stage I lung cancer who are not candidates for surgery. Consideration of SBRT to treat patients with stage I NSCLC who are medically fit for operation has resulted in the launching of 3 randomized controlled clinical trials (ROSEL, STARS, ACOSOG Z4099) comparing lobectomy with SBRT for operable stage I NSCLC, each of which closed prematurely because of poor accrual. In the absence of randomized data, 2 bodies of lower-level evidence literature on the comparative efficacies of surgery and SBRT for stage I lung cancer have emerged, one from the surgical community and one from the radiation oncology community. Sampling articles from each side of the aisle is an educational exercise that will benefit the reader's understanding of the disparities in outcomes reporting between each discipline and their implications for interpretation of results. Recently, the American Society

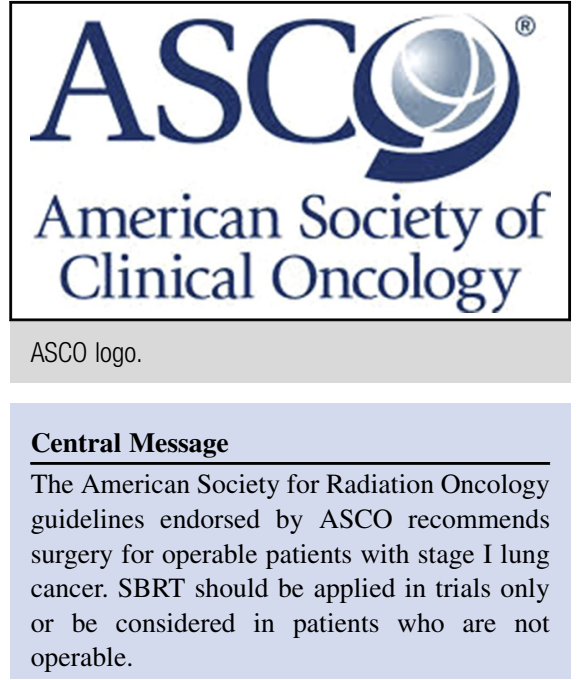

for Radiation Oncology (ASTRO) published a refreshing evidence-based guideline on the role of SBRT in early stage NSCLC that was endorsed by the American Society of Clinical Oncology (ASCO). According to these guidelines, SBRT is not recommended as an alternative to surgery for patients with stage I NSCLC and standard operative risk, outside the context of a clinical trial. The Feature Expert Opinion article that follows is an interdisciplinary collaboration of surgery, radiation oncology, and pulmonology that will prime the readers on the most salient aspects of the ASTRO and ASCO guidelines for SBRT and offers a practical perspective for implementing these guidelines into practice.

Bryan M. Burt, MD

We have witnessed controversies within the thoracic oncology community about the optimal treatment of early-stage non-small cell lung cancer (NSCLC), for which surgical lobectomy is challenged by stereotactic body radiotherapy (SBRT), and in the absence of randomized controlled trials, thoracic surgeons and radiation oncologists interpreted the available data in different ways. Therefore, the American Society for Radiation Oncology generated an evidence-based guideline on the role of SBRT in early-stage NSCLC: This guideline was 
co-authored by thoracic surgeons and radiation oncologists and was endorsed by the American Society of Clinical Oncology (ASCO) after being updated with recent publications and amended by medical oncologists and pulmonologists apart from the ASCO radiation oncologists and thoracic surgeons. ${ }^{1,2}$ We congratulate our colleagues and their societies for coming to this consensus. It is the aim of this expert opinion statement to share the interdisciplinary views of thoracic surgery, pulmonology, and radiation oncology on how to interpret and translate the updated guideline by ASCO into clinical practice. We want to specifically address the situation of operable patients.

Recommendation 1A: Patients with stage I NSCLC should be evaluated by a thoracic surgeon, preferably within a multidisciplinary cancer care team, to determine operability. The decision to undergo an operation should be made by the surgeon and patient, in collaboration with family members. (Strength of recommendation: strong; Quality of evidence: moderate.)

Despite a low level of evidence supporting this statement by literature, the surgeon who is taking over the responsibility for surgery knows best how to assess and avoid risk and therefore determine operability. Nevertheless, we strongly advocate to discuss all patients with lung cancer within the structures of certified cancer centers and within multidisciplinary team meetings, which integrate the complementary knowledge and expertise of all disciplines involved in lung cancer management: thoracic surgery, radiation oncology, medical oncology, pulmonology, diagnostic radiology and nuclear medicine, and pathology. A recent systematic review reported that between $4 \%$ and $45 \%$ of patients discussed at multidisciplinary team meetings experience changes in diagnostic reports after the meeting; changes in the treatment plan were made in up to $34.5 \%$ of the patients. ${ }^{3}$ For early-stage NSCLC, discussion at multidisciplinary team meetings increases the proportion of patients treated with curative intent. ${ }^{4}$

After discussion of the multidisciplinary team meeting, patients with standard operative risk are informed and consented by the thoracic surgeon. Involvement of the patient's family members in a shared decision-making process is considered important to achieve a realistic perception of the benefits and risks associated with a curative treatment intent. ${ }^{5}$

Recommendation 1B: For patients with standard operative risk and stage I NSCLC, SBRT is not recommended as an alternative to surgery outside of a clinical trial. Discussions about SBRT among members of the multidisciplinary cancer care team may be appropriate. For this population, lobectomy with systematic mediastinal/ hilar lymph node evaluation remains the recommended treatment, although a sublobar resection may be considered in select clinical scenarios (Strength of recommendation: strong; Quality of evidence: high.)

There is strong agreement that surgical lobectomy with hilar and mediastinal lymph node dissection is the standard of care in appropriately selected patients with stage I NSCLC. Despite being published more than 20 years ago, the randomized trial by Ginsberg and Rubinstein ${ }^{6}$ is still defining the standard of care, with lobectomy being superior to limited resection in terms of locoregional disease control and survival. Although some, but not all, retrospective studies suggest similar outcomes of lobectomy and sublobar anatomic resection for selected patients, in particular those with small in situ or minimally invasive lung cancers, lobectomy remains the standard of care in the absence of randomized evidence. ${ }^{7,8}$ In any case, thoracic surgeons should aim for a complete R0 resection with adequate lymph node evaluation that implies a systematic or at least a lobe-specific systematic lymph node dissection. ${ }^{9}$ So-called uncertain resections by, for example, less rigorous lymph node evaluation should be avoided because they carry a poorer prognosis. ${ }^{10}$

Three randomized trials (ROSEL, STARS, American College of Surgeons Oncology Group Z4099 trial) have aimed at comparing SBRT and lobectomy in operable patients with stage I NSCLC, and all trials were closed early because of poor patient recruitment. A pooled analysis of 2 trials (ROSEL, STARS) has been published and reported reduced morbidity and no inferior overall survival, recurrence-free survival, and recurrence pattern of SBRT compared with lobectomy. ${ }^{11}$ However, the small number of patients $(n=58)$ makes interpretation of these data difficult and was therefore critically commented. Many studies have performed propensity-score analyses of SBRT versus surgical treatment based on retrospective single- or multiple institution data or population-based data (Surveillance, Epidemiology, and End Results; National Cancer Database), and results have been summarized in a recent meta-analysis. ${ }^{12}$ The authors reported a significant overall survival advantage in favor of lobectomy, whereas no differences were observed for lung cancer-specific survival.

It is important that the appropriateness of lobectomy as standard of care is specified explicitly for patients with standard operative risk only. Standard risk is quantified in 2 aspects: (1) the patient individual operative mortality risk and (2) pulmonary function. The American Society for Radiation Oncology guideline has defined the threshold of standard-risk patients with an anticipated operative mortality of less than $1.5 \%$, whereas ASCO has not endorsed this fixed threshold of $1.5 \%$ mortality. On the basis of the US National Cancer Database and 57,864 patients treated with lobectomy, the overall 30-day and 90-day mortality was $2.00 \%$ and $3.46 \%$, respectively. ${ }^{13}$ Standard operative risk of $1.5 \%$ was observed in patients 
with a maximum age of 65 years and reached $4.44 \%$ for patients aged 81 years or more. Patient age is certainly an important risk factor; however, we strongly agree that age alone is insufficient for estimating the operative risk and selecting patients for lobectomy. Besides age, male sex, cardiovascular and pulmonary comorbidities, and the patient's functional status are known factors influencing the operative risk and need to be considered in the decision-making process. Therefore, we recommend using quantitative scores for patient individual operative risk assessment and considering these in the process of patient selection. ${ }^{14-16}$ Beyond patient characteristics influencing the operative risk, surgical experience is a documented factor affecting overall survival after pulmonary surgery and specialized centers have reported a surgical mortality after lobectomy less than $1 \%$ after minimally invasive resection by video-assisted thoracic surgery or robotic-assisted resection. ${ }^{17}$ However, systematic studies analyzing the effect of surgical volume and expertise on perioperative mortality showed only mixed results regarding perioperative mortality risk in high-volume centers. ${ }^{18-20}$ We recommend that patients undergo operation at high-volume centers by surgeons with sufficient experience; however, estimation of the operative risk and consequently the indication for lobectomy should be based on the published risk models.

Regarding pulmonary function, we agree with the guideline that high operative risk is defined by preoperative forced expiratory volume in 1 second less than $50 \%$ predicted and diffusing capacity of the lungs for carbon monoxide less than $50 \%$ predicted. In addition, predicted postoperative values of less than $40 \%$ forced expiratory volume in 1 second and diffusing capacity of the lungs for carbon monoxide have been suggested to identify high-risk patients. ${ }^{21}$ The location of the tumor also should be considered: When located in a functionally and structurally void area in appropriately selected patients with advanced emphysema, a volume reduction effect after surgical resection may be observed, giving rise to only a limited reduction or even an improvement of lung function parameters postoperatively. ${ }^{22}$

Recommendation 1C: For patients with high operative risk stage I NSCLC, discussions about SBRT as a potential alternative to surgery are encouraged within the multidisciplinary cancer care team. When SBRT is offered to patients, they should be informed that although SBRT may have decreased risks from treatment in the short term, the longer-term outcomes at more than 3 years are not well established. (Strength of recommendation: conditional; Quality of evidence: moderate.)

Sublobar anatomic resection of segmentectomy combined with mediastinal lymph node dissection is a frequent practice in patients at increased risk for lobectomy. The US National Cancer Database identified 15,189 patients treated with sublobar resection, and the overall 30-day mortality was $1.77 \%$ compared with $2.00 \%$ after lobectomy. The standard risk of $1.5 \%$ was exceeded for patients aged more than 70 years. Data of the American College of Surgeons National Surgical Quality Improvement Program database were used for modeling the risk of operative mortality between lobectomy and segmentectomy, and 2 risk groups have been proposed ${ }^{15}$; however, operative mortality was identical with $1.2 \%$ in the low-risk group and exceeded the $1.5 \%$ threshold in the high-risk group for both segmentectomy $(3.6 \%)$ and lobectomy $(4.9 \%)$.

Randomized studies comparing sublobar resection and SBRT are not available, and results of retrospective studies are conflicting. Although a systematic review of studies using propensity score analyses reported better overall survival comparing sublobar resection with SBRT and no difference in lung cancer-specific survival, ${ }^{12}$ a large analysis among US veterans reported no difference in cancer-specific survival, noncancer survival, and overall survival between patients treated with sublobar resection $(\mathrm{n}=634)$ and patients treated with SBRT $(\mathrm{n}=449) .{ }^{23} \mathrm{In}$ the near future, results from several randomized trials comparing sublobar resection with lobectomy will be reported.

We agree that data on the long-term outcomes of SBRT are still limited; however, several prospective phase II trials of SBRT reported outcome with follow-up greater than 3 to 5 years, and all did not observe an increased risk of late recurrences or risk of death. ${ }^{24-27}$ It should also be pointed out that response assessment after SBRT is more difficult because of fibrotic changes in the high-dose volumes, and in most reports local control after SBRT is defined as "absence of progressive disease" in contrast to surgery where no tumor remains after complete R0 resection. ${ }^{28}$ However, computed tomography-based criteria for differentiation of fibrotic changes and true local progression recently have been developed and validated ${ }^{29,30}$ Because of the limited negative predictive value of positron emission tomography-computed tomography, especially in patients with T2 or central tumors, those patients treated with SBRT may undergo more detailed lymph node evaluation by minimally invasive or invasive staging techniques as N1 or N2 involvement. ${ }^{31}$ Prospective trials evaluating the impact of invasive staging before SBRT are still running and should be awaited before changing standard practice.

We recommend that patients with an increased operative risk are jointly informed by a thoracic surgeon and radiation oncologist about the risks and benefits of segmentectomy versus SBRT. Joint consultations will give the most balanced information to the patient and simultaneously will contribute to further improve the mutual understanding of thoracic surgeons and radiation oncologists. 
With the existing data, the mentioned recommendations and our interpretation should guide the patient and the physician to optimal treatment for early-stage NSCLC.

\section{Conflict of Interest Statement}

Authors have nothing to disclose with regard to commercial support.

\section{References}

1. Videtic GMM, Donington J, Giuliani M, Heinzerling J, Karas TZ, Kelsey CR, et al. Stereotactic body radiation therapy for early-stage non-small cell lung cancer: Executive Summary of an ASTRO Evidence-Based Guideline. Pract Radiat Oncol. 2017; 7:295-301.

2. Schneider BJ, Daly ME, Kennedy EB, Antonoff MB, Broderick S, Feldman J, et al. Stereotactic body radiotherapy for early-stage non-small-cell lung cancer: American Society of Clinical Oncology endorsement of the American Society for radiation oncology evidence-based guideline. J Clin Oncol. 2017. JCO2017749671.

3. Pillay B, Wootten AC, Crowe H, Corcoran N, Tran B, Bowden P, et al. The impact of multidisciplinary team meetings on patient assessment, management and outcomes in oncology settings: a systematic review of the literature. Cancer Treat Rev. 2016;42:56-72.

4. Stevens W, Stevens G, Kolbe J, Cox B. Management of stages I and II non-smallcell lung cancer in a New Zealand study: divergence from international practice and recommendations. Intern Med J. 2008;38:758-68.

5. Kim Y, Winner M, Page A, Tisnado DM, Martinez KA, Buettner S, et al. Patient perceptions regarding the likelihood of cure after surgical resection of lung and colorectal cancer. Cancer. 2015;121:3564-73.

6. Ginsberg RJ, Rubinstein LV. Randomized trial of lobectomy versus limited resection for T1 N0 non-small cell lung cancer. Lung Cancer Study Group. Ann Thorac Surg. 1995;60:615-23.

7. Landreneau RJ, Normolle DP, Christie NA, Awais O, Wizorek JJ, Abbas G, et al. Recurrence and survival outcomes after anatomic segmentectomy versus lobectomy for clinical stage I non-small-cell lung cancer: a propensity-matched analysis. J Clin Oncol. 2014;32:2449-55.

8. Sihoe AD, Van Schil P. Non-small cell lung cancer: when to offer sublobar resection. Lung Cancer. 2014;86:115-20.

9. Rami-Porta R, Wittekind C, Goldstraw P, International Association for the Study of Lung Cancer Staging Committee. Complete resection in lung cancer surgery: proposed definition. Lung Cancer. 2005;49:25-33.

10. Gagliasso M, Migliaretti G, Ardissone F. Assessing the prognostic impact of the International Association for the Study of Lung Cancer proposed definitions of complete, uncertain, and incomplete resection in non-small cell lung cancer surgery. Lung Cancer. 2017;111:124-30.

11. Chang JY, Senan S, Paul MA, Mehran RJ, Louie AV, Balter P, et al. Stereotactic ablative radiotherapy versus lobectomy for operable stage I non-small-cell lung cancer: a pooled analysis of two randomised trials. Lancet Oncol. 2015;16:630-7.

12. Chen H, Laba JM, Boldt RG, Goodman CD, Palma DA, Senan S, et al. Stereotactic ablative radiation therapy versus surgery in early lung cancer: a metaanalysis of propensity score studies. Int J Radiat Oncol Biol Phys. 2018;101: 186-94.

13. Stokes WA, Bronsert MR, Meguid RA, Blum MG, Jones BL, Koshy M, et al. Post-treatment mortality after surgery and stereotactic body radiotherapy for early-stage non-small-cell lung cancer. J Clin Oncol. 2018. JCO2017756536.

14. Kates M, Perez X, Gribetz J, Swanson SJ, McGinn T, Wisnivesky JP. Validation of a model to predict perioperative mortality from lung cancer resection in the elderly. Am J Respir Crit Care Med. 2009;179:390-5.
15. Gulack BC, Yang CJ, Speicher PJ, Yerokun BA, Tong BC, Onaitis MW, et al. A risk score to assist selecting lobectomy versus sublobar resection for early stage non-small cell lung cancer. Ann Thorac Surg. 2016;102:1814-20.

16. Jean RA, DeLuzio MR, Kraev AI, Wang G, Boffa DJ, Detterbeck FC, et al Analyzing risk factors for morbidity and mortality after lung resection for lung cancer using the NSQIP database. J Am Coll Surg. 2016;222:992-1000 e1001.

17. Burt BM, Kosinski AS, Shrager JB, Onaitis MW, Weigel T. Thoracoscopic lobectomy is associated with acceptable morbidity and mortality in patients with predicted postoperative forced expiratory volume in 1 second or diffusing capacity for carbon monoxide less than $40 \%$ of normal. J Thorac Cardiovasc Surg. 2014; 148:19-29.e11.

18. von Meyenfeldt EM, Gooiker GA, van Gijn W, Post PN, van de Velde CJ, Tollenaar RA, et al. The relationship between volume or surgeon specialty and outcome in the surgical treatment of lung cancer: a systematic review and meta-analysis. J Thorac Oncol. 2012;7:1170-8.

19. Falcoz PE, Puyraveau M, Rivera C, Bernard A, Massard G, Mauny F, et al The impact of hospital and surgeon volume on the 30-day mortality of lung cancer surgery: a nation-based reappraisal. J Thorac Cardiovasc Surg. 2014;148:841-8.

20. Smith CB, Wolf A, Mhango G, Wisnivesky JP. Impact of surgeon volume on out comes of older stage I lung cancer patients treated via video-assisted thoracoscopic surgery. Semin Thorac Cardiovasc Surg. 2017;29:223-30.

21. Donington J, Ferguson M, Mazzone P, Handy J Jr, Schuchert M, Fernando H et al. American College of Chest Physicians and Society of Thoracic Surgeons consensus statement for evaluation and management for high-risk patients with stage I non-small cell lung cancer. Chest. 2012;142:1620-35.

22. Korst RJ, Ginsberg RJ, Ailawadi M, Bains MS, Downey RJ Jr, Rusch VW, et al. Lobectomy improves ventilatory function in selected patients with severe COPD Ann Thorac Surg. 1998;66:898-902.

23. Bryant AK, Mundt RC, Sandhu AP, Urbanic JJ, Sharabi AB, Gupta S, et al. Stereotactic body radiation therapy versus surgery for early lung cancer among US veterans. Ann Thorac Surg. 2018;105:425-31.

24. Fakiris AJ, McGarry RC, Yiannoutsos CT, Papiez L, Williams M, Henderson MA, et al. Stereotactic body radiation therapy for early-stage nonsmall-cell lung carcinoma: four-year results of a prospective phase II study. Int J Radiat Oncol Biol Phys. 2009;75:677-82.

25. Lindberg K, Nyman J, Riesenfeld Kallskog V, Hoyer M, Lund JA, Lax I, et al Long-term results of a prospective phase II trial of medically inoperable stage I NSCLC treated with SBRT - the Nordic experience. Acta Oncol. 2015;1-9.

26. Sun B, Brooks ED, Komaki RU, Liao Z, Jeter MD, McAleer MF, et al. 7-year follow-up after stereotactic ablative radiotherapy for patients with stage I nonsmall cell lung cancer: results of a phase 2 clinical trial. Cancer. 2017;123: 3031-9.

27. Shibamoto Y, Hashizume C, Baba F, Ayakawa S, Miyakawa A, Murai T, et al. Stereotactic body radiotherapy using a radiobiology-based regimen for stage I non-small-cell lung cancer: five-year mature results. J Thorac Oncol. 2015;10: 960-4.

28. Van Schil PE. Results of surgery for lung cancer compared with radiotherapy: do we speak the same language. J Thorac Oncol. 2013;8:129-30.

29. Huang K, Dahele M, Senan S, Guckenberger M, Rodrigues GB, Ward A et al. Radiographic changes after lung stereotactic ablative radiotherapy (SABR) - Can we distinguish recurrence from fibrosis? A systematic review of the literature. Radiother Oncol. 2012;102:335-42.

30. Peulen H, Mantel F, Guckenberger M, Belderbos J, Werner-Wasik M, Hope A et al. Validation of high-risk computed tomography features for detection of local recurrence after stereotactic body radiation therapy for early-stage non-small cell lung cancer. Int J Radiat Oncol Biol Phys. 2016;96:134-41.

31. Akthar AS, Ferguson MK, Koshy M, Vigneswaran WT, Malik R. Limitations of PET/CT in the detection of occult N1 metastasis in clinical stage I (T1-2aN0) non-small cell lung cancer for staging prior to stereotactic body radiotherapy Technol Cancer Res Treat. 2017;16:15-21. 